\title{
Comportamentos verbais do terapeuta no Sistema Multidimensional para a Categorização de Comportamentos na Interação Terapêutica*(SiMCCIT)
}

\section{Therapist verbal behavior in the Multidimensional System for Categorization of Behaviors in Therapeutic Interaction (SiMCCIT)}

\section{Denis Zamignani ${ }^{1}$ e Sonia Beatriz Meyer ${ }^{2}$}

[1] Núcleo Paradigma de Análise do Comportamento, Brasil [2] Universidade de São Paulo (USP), Brasil | Título abreviado: Categorização de comportamentos verbais do terapeuta analítico-comportamental | Endereço para correspondência: Denis Zamignani. Rua Wanderley, 611. CEP: 05011-001. São Paulo, SP. | E-mail: denis@nucleoparadigma.com.br

Resumo: A interação terapêutica tem sido compreendida como um dos principais fatores de mudança na psicoterapia. Sua investigação é denominada pesquisa de processo. Ela conta com o registro de sessões em áudio e/ou vídeo para a categorização de comportamentos e a análise posterior de padrões de interação. O presente trabalho teve como objetivo a apresentação de parte do Sistema Multidimensional para a Categorização de Comportamentos na Interação Terapêutica (SiMCCIT) e da avaliação da concordância entre observadores ao utilizá-lo. A partir de uma análise sistemática da literatura referente à classificação de comportamentos verbais vocais, constatou-se que os sistemas de categorias já existentes não eram satisfatórios para o estudo da terapia analítico-comportamental, exigindo a construção de um novo sistema. Desenvolveu-se então o Sistema de Categorização de Comportamentos Verbais do Terapeuta, composto por 16 categorias, nove delas referentes a comportamento verbal vocal, quatro a comportamento verbal não vocal e três categorias residuais. Elaborou-se ainda um treino padronizado para observadores, cuja aplicação a um participante produziu índices de concordância Kappa satisfatórios (0.67 e 0.84). São discutidas as implicações do uso do sistema para a pesquisa de processo em terapia analítico-comportamental e em outras modalidades terapêuticas em suas diferentes etapas, assim como a possibilidade de uso do instrumento e do software de treino para o ensino de habilidades terapêuticas.

Palavras-chave: pesquisa de processo em psicoterapia, categorização de comportamentos, interação terapeuta-cliente, terapia analítico-comportamental

\begin{abstract}
Therapeutic interaction has been considered one of the main factors of change in psychotherapy, and its investigation is called process research. Audio and video recording sessions are used to code behaviors which, subsequently, permit the analysis of interaction patterns. The objectives of the study were the presentation of part of a coding system called "Multidimensional System for Categorization of Behaviors in Therapeutic Interaction" and the evaluation of agreement between observers in its use. From a systematic assessment of the literature regarding the classification of vocal verbal behavior, it was found that the existing category systems were not satisfactory for the study of behavior analytic therapy, thus requiring the construction of a new system. A System for Coding Verbal Therapist Behavior was developed containing 16 categories, nine of vocal verbal behavior, three for non vocal verbal behavior and four residual categories. A standardized training for observers was also developed. Its application to one participant produced satisfactory Kappa indexes of agreement ranging from 0.67 to 0.84 . The implications of using the system for process research in behavior analytic therapy and in other therapeutic modalities in its different stages are discussed as well as the possibility of using the instrument and its training software for teaching therapeutic skills.
\end{abstract}

Keywords: therapeutic process research, categorization of behaviors, client-therapist interaction, behavior-analytic therapy

* Trabalho parcialmente financiado pela FAPESP (processo 04/05840-8). Bolsista CAPES doutorado (março de 2004 a fevereiro de 2005). 
A interação terapêutica tem sido o objeto de estudo de pesquisadores de diferentes abordagens teóricas e áreas do conhecimento. Nas chamadas pesquisas de processo (Greenberg \& Pinsof, 1986; Russel \& Trull, 1986), visa-se a caracterizar a interação (verbal e não verbal) entre terapeuta e cliente, de modo a identificar os processos de mudança que ocorrem nessa interação. Luna (1997) observa que a clínica é um ambiente privilegiado para o desenvolvimento da pesquisa. Nesta situação, temos acesso a dados de relato verbal que, de outra forma, dificilmente poderiam ser obtidos. O pesquisador, neste ambiente de pesquisa, pode ter grande controle sobre o contexto no qual esse tipo de comportamento ocorre, além de contar com participantes de pesquisa que se apresentam com regularidade por longos períodos de tempo, permitindo repetidas observações do fenômeno de interesse.

Um dos métodos mais utilizados para este fim é a observação direta de sessões gravadas em áudio e/ou em vídeo e a classificação dos dados por meio de categorias de comportamento. A partir da categorização dos comportamentos observados, são conduzidas análises das relações entre essas categorias, de forma a identificar possíveis efeitos de diferentes classes de comportamento de um membro da díade sobre o outro (Russel \& Trull, 1986; Wampold, 1986).

Nas últimas décadas, o número de pesquisadores que têm se dedicado a este tipo de pesquisa é expressivo (e.g., Almásy, 2004; Baptistussi, 2001; Barbosa, 2001; Barbosa, 2006; Bischoff \& Tracey, 1995; Brandão, 2003; Chamberlain \& Ray, 1988; Chamberlain, Patterson, Reid, Kanavagh \& Forgatch, 1984; Donadone, 2004; Garcia, 2001; Hill, 1986; Hill, Corbett, Kanitz, Rios, Lightsey \& Gomez, 1992; Maciel, 2004; Martins, 1999; Meyer \& Donadone, 2002; Moreira, 2001; Nardi, 2004; Novaki, 2003; Oliveira, 2002; Silva, 2001; Tourinho, Garcia \& Souza, 2003; Vermes, 2000; Yano, 2003; Zamignani \& Andery, 2005). Ao mesmo tempo, são diversos os temas investigados e os recursos metodológicos desenvolvidos para a análise, produzindo dados bastante esclarecedores para o entendimento das relações que ocorrem na psicoterapia.

Diferentes sistemas de categorização foram desenvolvidos especificamente para a análise da interação terapeuta-cliente (e.g., Baptistussi, 2001; Bischoff \& Tracey, 1995; Brandão, 2003; Britto,
Oliveira \& Sousa, 2003; Chamberlain \& Ray, 1988; Chamberlain, Patterson, Reid, Kanavagh \& Forgatch, 1984; Donadone, 2004; Garcia, 2001; Hill, 1986; Hill, Corbett, Kanitz, Rios, Lightsey \& Gomez, 1992; Margotto, 1998; Martins, 1999; Moreira, 2001; Novaki, 2003; Oliveira, 2002; Tourinho, Garcia, \& Souza, 2003; Vermes, 2000; Yano, 2003; Zamignani \& Andery, 2005).

Muitos desses sistemas apresentam categorias que descrevem classes de comportamentos bastante semelhantes, mas utilizam diferentes denominações e definições, existindo incompatibilidade entre eles em função da diferença entre os elementos destacados por cada um dos pesquisadores. Além disso, os estudos da área investigam, em geral, apenas comportamento verbal vocal. O estudo de respostas verbais vocais na psicoterapia vem sendo conduzido desde o final da década de 1960 e tem trazido importantes contribuições, mas sabe-se que parte importante da interação terapêutica é de natureza não vocal (Mahl, 1987).

O desenvolvimento de instrumentos para a categorização de comportamentos (e.g., Hill, 1986; Rice \& Kerr, 1986) envolve algumas etapas, que devem ser cumpridas para garantir a sua validação e fidedignidade. De acordo com Rice e Kerr (1986), a primeira dessas etapas implica a consolidação de uma base teórico-clínica, a qual deve fundamentar a elaboração de categorias segundo o campo de estudo adotado pelo pesquisador. Tal base é a condição para que o sistema desenvolvido apresente em suas categorias os elementos (comportamentos e contextos de ocorrência) característicos da modalidade de intervenção referente à linha teórica adotada (incluindo comportamentos que devem ocorrer e aqueles que devem ser evitados devido à sua inconsistência ou inadequação). Esta etapa envolveria, de acordo com Rice e Kerr, extensiva observação clínica e intensivas análises de registros em áudio ou em vídeo, além de consulta à teoria e ao julgamento clínico dos terapeutas envolvidos.

A segunda etapa, proposta por Rice e Kerr (1986), consiste na especificação dos elementos por meio dos quais os comportamentos em cada classe podem ser reconhecidos. Esta etapa envolveria uma descrição precisa desses comportamentos, o que, segundo os autores, exige um cuidado para que o instrumento seja o mais descritivo e o menos 
inferencial possível. Quanto mais descritivo, afirmam, menor será a complexidade da observação e maior a possibilidade de uso do sistema em diferentes campos e abordagens de estudo. $\mathrm{O}$ produto concreto desta segunda fase, de acordo com Rice e Kerr, seria um manual detalhado para treino de observadores.

De acordo com Danna e Matos (1999), a definição de um evento em uma dada categoria deve “(1) ser objetiva, clara e precisa; (2) ser expressa na forma direta e afirmativa; (3) incluir somente elementos que lhe sejam pertinentes; (4) ser explícita e completa” (p. 134). Além disso, a definição não pode ser "circular", ou seja, o termo definido não pode ser utilizado em sua própria definição (Marinotti, 2000) e devem ser evitados termos subjetivos, fatos interpretados ou inferidos (Cunha, 1975; Fagundes, 1976/1992). É necessário considerar também a necessidade de que o sistema seja suficientemente sensível para responder às questões colocadas sem, no entanto, ser excessivamente detalhado, o que produziria dispersão nos resultados (Wampold, 1986; Zamignani, 2001).

A fim de manter a coerência e a validade interna do sistema de categorias, deve-se também obedecer a alguns critérios: (a) as categorias construídas devem ser exaustivas ${ }^{1}$ e mutuamente excludentes; (b) todos os comportamentos observados e registrados devem ser classificados, independentemente do número de eventos que sejam categorizados em cada classe; (c) as categorias devem apresentar coerência quanto aos critérios escolhidos para a classificação e quanto ao grau de especificidade adotado para as classes de eventos (Danna \& Matos, 1999). Rice e Kerr (1986) sugerem ainda que esta segunda etapa seja proximamente relacionada à terceira, a qual envolve a obtenção de um grau adequado de concordância entre observadores, já que o pesquisador precisa transitar diversas vezes entre as duas etapas.

1 O termo exaustiva refere-se à "necessidade de que todo e qualquer comportamento relevante possa ser englobado em alguma das categorias" (Marinotti, 2000, p. 7) do sistema, ou seja, o sistema deve conter tantas categorias quanto necessário para englobar as classes de comportamento de interesse, incluindo uma categoria residual para abarcar as classes de comportamento não contempladas nas categorias desenvolvidas (Marinotti, 2000).
A quarta etapa na elaboração de um instrumento, de acordo com Rice e Kerr (1986), diz respeito ao estabelecimento da validade preditiva do sistema - o que implica verificar a sensibilidade do instrumento a padrões de interação que estejam sistematicamente relacionados ao sucesso ou insucesso da intervenção terapêutica. Esta tarefa é bastante complexa e envolveria a aplicação do instrumento na investigação de um conjunto amplo de interações terapêuticas, nas quais os dados possam ser relacionados com resultados.

A última etapa do desenvolvimento de um instrumento de observação, segundo Rice e Kerr (1986), consiste em estabelecer a validade de construto de suas categorias. A validade de constructo compreende as evidências que indicam quão bem os dados obtidos por meio de um instrumento refletem um constructo em particular ${ }^{2}$ (Kazdin, 2002). Quando evidências diretas não podem ser obtidas, evidências circunstanciais do constructo são reunidas de forma a dar suporte à assunção de que a medida reflete o constructo em estudo (Cronbach \& Meehl, 1955; Suen \& Ary, 1989).

Uma questão importante a ser destacada é que a categorização de eventos representa (e deve representar) apenas uma etapa da pesquisa, responsável pelo mapeamento inicial de processos "genéricos" que ocorrem na interação terapêutica. Quando a categorização de eventos não é associada a nenhum outro tipo de medida, ela oferece, no máximo, uma descrição da interação em curso, mas esta descrição não permite a identificação de variáveis de controle ou a inferência de generalizações sobre o fenômeno estudado. Devido ao avanço das pesquisas de processo em psicoterapia nas últimas décadas, hoje temos instrumentos disponíveis para a avaliação dos mais diversos aspectos da interação. A associação de categorias descritivas com outros instrumentos - de medida de resultado (Rice \& Kerr, 1986), de impacto da sessão (Stiles, 1980) ou outros - pode proporcionar informações muito mais ricas a respeito da interação estudada.

2 O termo constructo refere-se às características a serem estudadas ou detectadas pelo instrumento, enquanto medidas são as formas por meio das quais esses constructos são operacionalizados (Kazdin, 2002). 
Zamignani (2007) realizou uma avaliação sistemática da literatura sobre categorização de eventos verbais da interação terapêutica, em busca de elementos para o estudo da terapia analítico-comportamental. Nesse trabalho, o autor analisou sete sistemas de categorização de comportamento verbal vocal do terapeuta: (a) Therapy Process Code (Chamberlain \& Ray 1988); (b) Therapist Behavior Code (Ford, 1978); (c) Hill Counselor Verbal Response Modes (Hill, 1978); (d) Category System for Coding Interaction in Psychotherapy (Schindler, Hohenberger-Sieber \& Hahlweg, 1989); (e) Verbal Response Modes Coding System (Stiles, 1992); (f) Categorias Relativas às Funções Básicas das Verbalizações de Terapeutas (Tourinho, Garcia \& Souza, 2003) e (g) Categorias de Registro do Comportamento do Terapeuta (Zamignani, 2001).

Os critérios desenvolvidos por Zamignani (2007) para a análise sistemática dos instrumentos foram os seguintes: (a) Categorias e definições: este critério contemplou a clareza na definição das categorias de cada sistema, a construção das mesmas a partir de eventos diretamente observáveis ou que exigissem um mínimo de inferência e a consistência entre a descrição e a denominação das categorias; (b) Coerência do conjunto: este critério se referia à coerência interna do sistema, especialmente quanto à natureza (topográfica e/ou funcional) dos eventos contemplados em cada uma das categorias e ao grau de especificidade das diferentes categorias; (c) Treino sistemático: este critério dizia respeito à existência ou não de manual ou treino sistemático de observadores; (d) Utilização prévia em pesquisas: este critério levava em consideração se o sistema havia sido adotado por outros pesquisadores ou em outros estudos do mesmo grupo de pesquisa; (e) Compatibilidade: este critério avaliava se as categorias do sistema haviam sido desenvolvidas para o estudo de terapia analítico-comportamental ou se suas definições eram compatíveis ou adaptáveis para o estudo da interação nessa abordagem.

Zamignani (2007) concluiu que nenhum dos sistemas analisados correspondia de forma satisfatória a todos os critérios propostos. Por esse motivo, o autor reexaminou as categorias e as definições que compunham cada um dos instrumentos e catálogos de comportamentos anteriormente analisados, agrupando-as segundo similaridades. Um novo sistema de categorias foi então desenvolvido, tendo como ponto de partida a análise e a reorganização das categorias dos sistemas anteriores. Além disso, foram considerados textos de revisão bibliográfica sobre a interação terapêutica (e.g., Meyer \& Vermes, 2001) e textos para a formação de terapeutas (e.g., Fiorini, 1995). Zamignani estudou ainda transcrições de sessões de terapia analítico-comportamental utilizadas em trabalhos prévios, considerando também a visão de clínicos e pesquisadores experientes em terapia analítico-comportamental, de modo a identificar variáveis não abordadas nos sistemas anteriores. As categorias foram então definidas com vistas a destacar comportamentos típicos da interação em terapia analítico-comportamental.

O Sistema Multidimensional de Categorização de Comportamentos da Interação Terapêutica (SiMCCIT) é composto por três eixos de categorização. Cada um deles representa uma dimensão ou aspecto do comportamento dos participantes, a saber: Comportamento Verbal, Temas e Respostas Motoras.

O presente trabalho é decorrente do estudo conduzido por Zamignani (2007). Tem como objetivo a apresentação de parte do sistema por ele construído, o SiMCCIT, e da avaliação da concordância entre observadores ao utilizá-lo. No recorte deste artigo, descreve-se o eixo de categorias verbais do terapeuta. O manual completo para categorização e treino sistemático de observadores consta de Zamignani (2007).

\section{Método}

\section{Participantes}

- Uma díade terapeuta-cliente para a gravação de sessões de atendimento, composta de um terapeuta analítico-comportamental do sexo masculino, com 25 anos de experiência clínica, e uma cliente de 32 anos, grávida, com queixa relacionada a problemas matrimoniais, sem diagnóstico psiquiátrico prévio. - Três juízas para o cálculo de concordância entre observadores. As juízas eram graduadas em psicologia, com formação clínica em análise do comportamento, experiência como terapeutas analítico-comportamentais há pelo menos dois anos e 
participantes de atividades do grupo de pesquisa sob coordenação da orientadora, segunda autora deste trabalho.

\section{Características do Sistema de Categorias}

Para o desenvolvimento do sistema de categorização, optou-se pela adoção de categorias cuja função é presumida a partir de sua forma gramatical (e.g., imperativa, interrogativa, etc.) e de sua relação com eventos imediatamente precedentes e subsequentes. Esta escolha se baseou em recomendação da literatura (e.g., Danna \& Matos, 1999; Marinotti, 2000) de que a categorização seja pautada em eventos diretamente observáveis. A identificação desses eventos, entretanto, não considera apenas a sua topografia, mas a relação com seu contexto de ocorrência (estratégia adotada também por Hill, 1986).

Outra decisão tomada foi a de não limitar o estudo da interação terapêutica à dimensão verbal vocal. Para isso, foram incluídas no sistema de categorização de comportamentos verbais as categorias de Gestos Comunicativos. Considerou-se que tais gestos tinham relação estreita com a comunicação verbal vocal (Caballo, 1993), exercendo função análoga às respostas verbais vocais. Em virtude desta escolha, decidiu-se pela análise de dados a partir do registro em vídeo, e não de transcrições de sessões terapêuticas.

A unidade de registro do sistema é definida como uma ação (segmento de verbalização ou resposta verbal não vocal) do terapeuta ou do cliente. Dada a função exercida no contexto imediato da sessão, a ação seria classificável de acordo com os critérios presentes em uma das categorias aqui definidas. Entende-se por segmento de verbalização um trecho da fala do participante que compõe uma unidade funcional, delimitada por qualquer mudança em características específicas da fala (e.g., classe, pausa, tema, etc.), apontadas na definição de cada categoria, ainda que dentro da mesma verbalização desse participante. Uma mesma verbalização, portanto, pode conter mais de um segmento de fala.

A partir do desenvolvimento da primeira versão do sistema de categorias, uma série de ensaios de aplicação do sistema foi conduzida, conforme descrito a seguir.

\section{Registro de sessões terapêuticas por meio do sistema preliminar de categorização.}

Com o auxílio do software The Observer ${ }^{3}$, o primeiro autor deste artigo (aqui denominado pesquisador) aplicou a versão preliminar do sistema de categorias a uma sessão terapêutica registrada em vídeo. Após essa categorização inicial, as dificuldades encontradas e as questões decorrentes foram consideradas, levando à revisão das categorias.

Efetuadas as alterações, novas sessões foram observadas e categorizadas pelo pesquisador e por dois observadores (Observadores 1 e 2). Esses observadores haviam participado do processo de elaboração das categorias e tiveram acesso ao material escrito com as definições do sistema, mas não ocorreu um treino formal para a sua utilização.

O método adotado para a obtenção de concordância entre observadores baseou-se na sequência e na duração dos episódios na comparação entre pares de observadores (sempre o pesquisador e cada um dos observadores). Este método, disponível no software The Observer, identifica as intersecções de tempo nas quais ambos os observadores utilizaram a mesma categoria, independentemente do instante de início do episódio categorizado.

O cálculo usado (naquele momento) foi o percentual de concordância, representado pela seguinte fórmula:

\footnotetext{
$\%$ concordância $=\frac{\# \text { tempo de eventos concordantes }}{(\# \text { tempo concordantes }+\# \text { tempo discordantes })} \times 100$
}

Uma vez que a concordância inicial entre o pesquisador e cada um dos observadores, bem como entre os Observadores 1 e 2, foi inferior a 40\%, o sistema de categorias foi revisto e aperfeiçoado, até que as categorias criadas fossem consideradas suficientemente abrangentes e precisas. Categorizadas algumas sessões e revisto o sistema, novo processo de categorização independente e análise de concordância foi realizado (desta vez, apenas entre o pesquisador e um dos observadores - o Observador 2).

3 Trata-se de um sistema informatizado para análise comportamental, desenvolvido pela Noldus Information Technologies, que permite a categorização diretamente pela observação do registro em áudio e vídeo. 
Uma única sessão terapêutica (Sessão 11) foi categorizada repetidamente por ambos os observadores e o refinamento do sistema ocorreu sucessivamente, até que se obtivesse um índice satisfatório.

Na ocasião, utilizou-se o coeficiente Kappa, sugerido pela literatura como um indicador mais confiável de concordância (Suen \& Ary, 1989). O método para a obtenção do índice (calculado por meio do software The Observer) foi baseado na sequência e duração dos episódios, resultando em um satisfatório coeficiente Kappa de 0.79 (percentual de concordância de 0.93 ), conforme ilustrado na Tabela 1. As discordâncias foram novamente examinadas e outro ajuste nas definições foi realizado.

\section{Tabela 1}

Valores Obtidos no Cálculo de Concordância entre o Pesquisador e o Observador 2, Referentes às Categorias Verbais, na Sessão 11

\section{Sessão 11: Dados referentes ao comportamento} verbal do terapeuta

\begin{tabular}{ll}
\hline Medida & Valor \\
\hline Duração (segundos) de concordâncias & 2907,64 \\
Duração (segundos) de discordâncias & 204,16 \\
Percentual de concordância & 93,44 \\
Índice de concordância & 0,93 \\
Coeficiente Kappa & 0,79 \\
\hline
\end{tabular}

Em seguida, uma sessão que ainda não havia sido categorizada por ambos (Sessão 17) foi então categorizada pelos mesmos observadores (pesquisador e Observador 2) independentemente, utilizando o método de cálculo mencionado. Mais uma vez, não ocorreu treino formal para essa etapa. $\mathrm{O}$ coeficiente Kappa obtido foi de 0.67 (percentual de concordância de 0.89), ainda considerado satisfatório, conforme ilustrado na Tabela 2 . Novos ajustes foram então realizados com base nas discordâncias obtidas, dando origem à versão final do sistema de categorização.

\section{Tabela 2}

Valores Obtidos no Cálculo de Concordância entre o Pesquisador e o Observador 2, Referentes às Categorias Verbais, na Sessão 17

Sessão 17: Dados referentes ao comportamento verbal do terapeuta

\begin{tabular}{ll}
\hline Medida & Valor \\
\hline Duração (segundos) de concordâncias & 2697,79 \\
Duração (segundos) de discordâncias & 343,97 \\
Percentual de concordância & 88,69 \\
Índice de concordância & 0,89 \\
Coeficiente Kappa & 0,67
\end{tabular}

\section{Versão final das categorias de comportamento verbal do SiMCCIT.}

A partir dos estudos de concordância, uma versão final do SiMCCIT foi proposta e um treino sistemático de observadores foi desenvolvido. Para o desenvolvimento do treino, optou-se por uma metodologia compatível com as propostas analítico-comportamentais de ensino individualizado (Holland \& Skinner, 1969/1975; Skinner, 1968/1972). Tinha-se em vista uma condição de treino na qual o observador pudesse emitir respostas de escolha, simultaneamente à apresentação das categorias. Esta condição de treino corresponde à noção de aprendizagem ativa, na qual respostas do indivíduo, a partir de uma instrução, são seguidas por consequências imediatas (Skinner, 1968/1972), aumentando-se gradualmente a dificuldade do conteúdo apresentado.

O treino contém dois pacotes de atividades sequenciais: 433 atividades divididas em 15 séries para treino das categorias referentes ao terapeuta e 265 atividades divididas em nove séries para as categorias referentes ao cliente ${ }^{4}$. As atividades foram desenvolvidas utilizando-se o software Clic ${ }^{\otimes 5}$.

4 O software de treinamento de observadores desenvolvido para este trabalho encontra-se em um mini-DVD anexo à tese de Zamignani (2007). No presente trabalho, será abordado apenas o treino com relação às categorias do terapeuta.

$5 \mathrm{O} \mathrm{Clic}^{\circledast} 3.0$ é um software livre, constituído por um conjunto de aplicações que permite criar diversos tipos de atividades educativas multimídia. Foi desenvolvido pelo Departamento de Educación de la Generalitat de Cataluña e pode ser obtido a partir do endereço eletrônico http://clic.xtec.cat/ 
As definições e as especificações de cada categoria são apresentadas de forma subdividida, em segmentos ao longo do treino. Cada tela do treino é composta por um segmento da definição de uma categoria, conforme a Figura 1.

Após a leitura de um segmento de definição, o observador deve clicar com o mouse sobre a tela de instrução, tendo acesso a um exercício correspondente ao trecho da categoria instruído. No exercício, ele é apresentado a uma situação de escolha entre dois trechos de transcrição de sessão, na qual deve selecionar aquela que corresponde à definição apresentada, conforme a Figura 2. O trecho de transcrição utilizado para comparação com o trecho correto é claramente diferente da categoria em questão, ou refere-se a outra categoria, previamente apresentada na sequência do treino.

No exercício em questão, em caso de erro, a casela de escolha torna-se vermelha e a tela de exercício permanece aberta. Em caso de acerto, o símbolo do cursor transforma-se indicando acerto e a tela muda automaticamente para o próximo segmento de instrução. Ao final de cada série (uma série compreende a apresentação integral de uma categoria), alguns exercícios adicionais são apresentados, aumentando a dificuldade da resposta de escolha, por meio da apresentação de trechos de interação que envolvem maior similaridade entre categorias. Além disso, também são apresentados alguns exercícios de comparação com trechos de sessão gravados em vídeo (os trechos em questão representam episódios fictícios de sessão, gravados por atores especialmente para este fim), conforme a Figura 3.

Ao final da apresentação de todas as categorias verbais e dos qualificadores, uma série de exercícios é apresentada, na qual o observador deve selecionar, dentre todas as categorias disponíveis, aquela que melhor representa o trecho de transcrição ou o vídeo apresentado, conforme a Figura 4 . A série final do treino apresenta instruções e critérios para a inserção das categorias no software The Observer ${ }^{\oplus}$.

Após o desenvolvimento do treino de observadores, um novo observador (o Observador 3 - que não havia participado do processo prévio de elaboração e avaliação das categorias) foi a ele submetido. O software de treino foi instalado em um notebook, de modo que o observador realizou o treino em sua própria residência. Após o treino padronizado, o Observador 3 foi orientado para o ma-

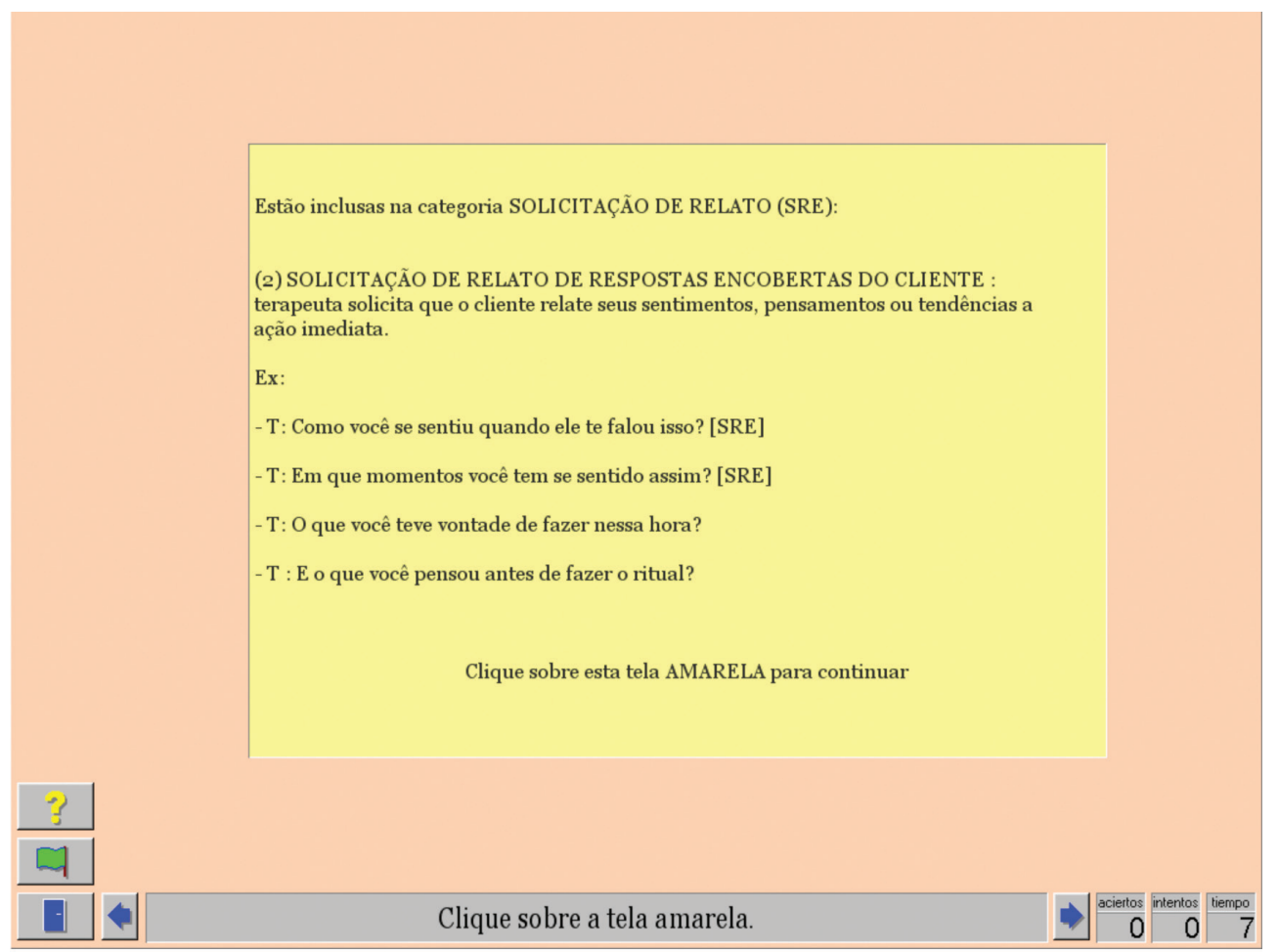

Figura 1. Exemplo de tela de treino na qual é apresentado um segmento de definição da categoria Solicitação de Relato do terapeuta. 


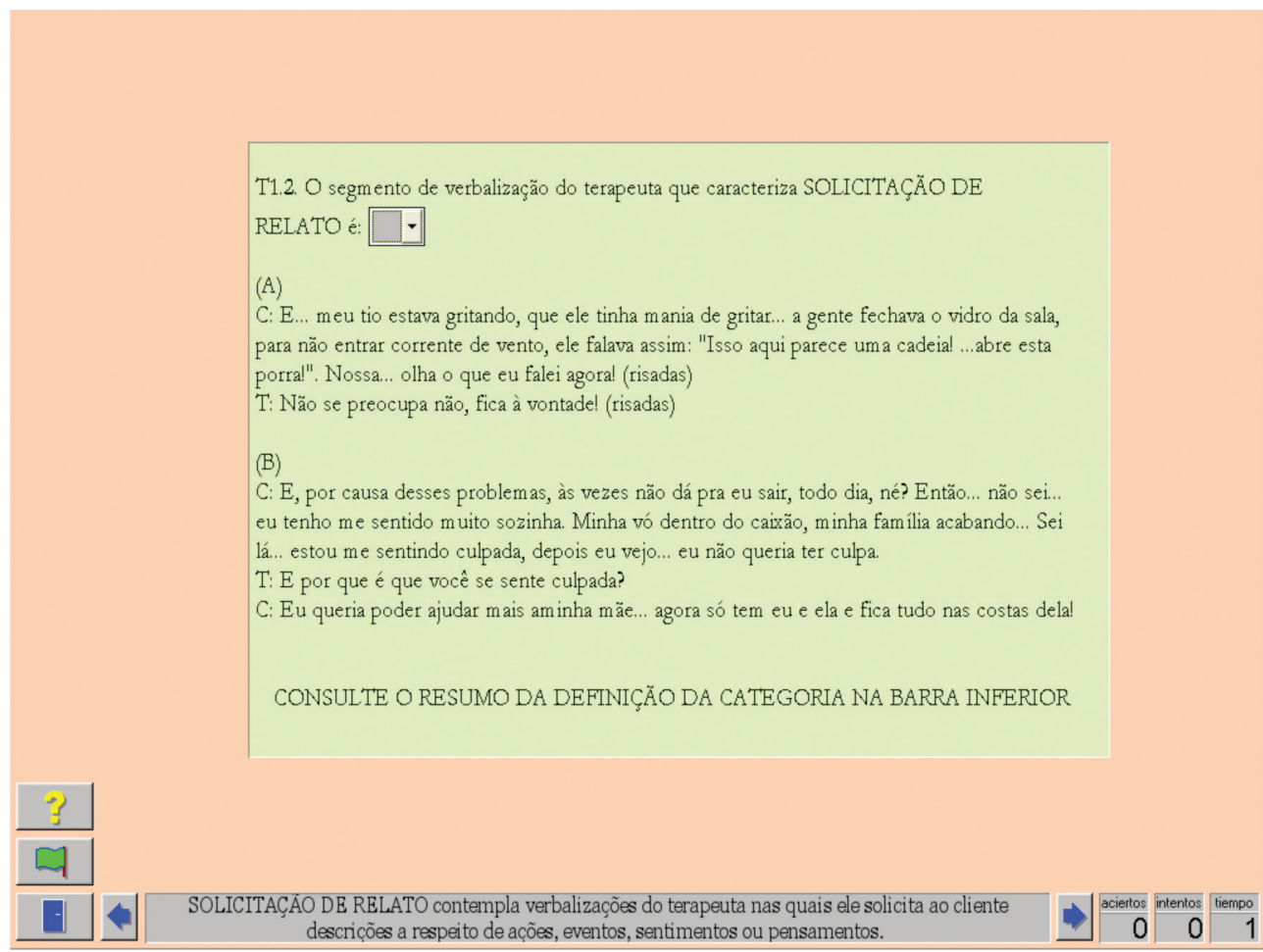

Figura 2. Exemplo de tela de treino na qual é apresentada uma atividade de identificação da categoria Solicitação de Relato do terapeuta.

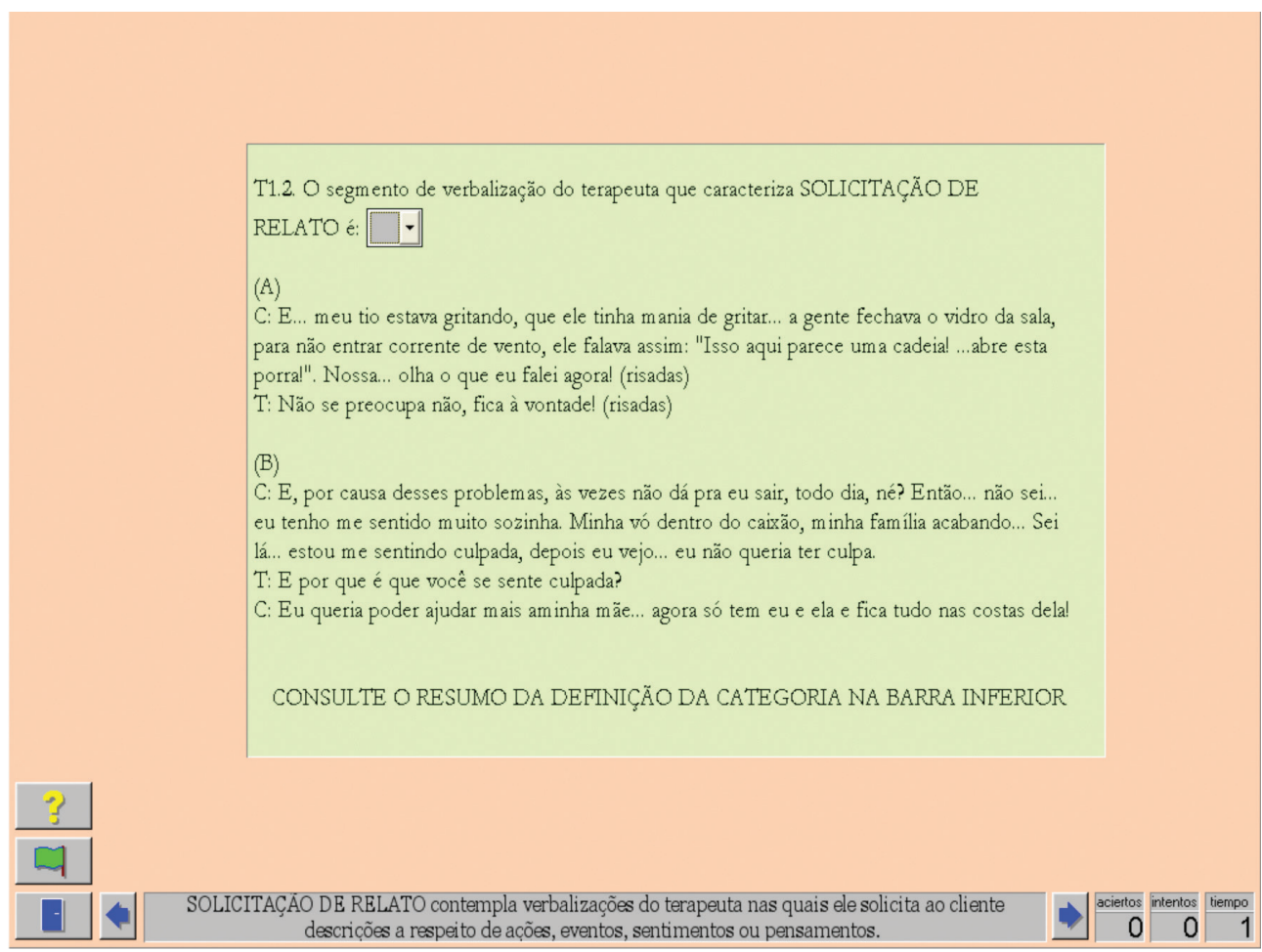

Figura 3. Exemplo de tela de treino na qual é apresentada uma atividade de identificação da categoria Solicitação de Relato do terapeuta a partir de trechos fictícios de sessão terapêutica, gravados em vídeo. 
nuseio do software The Observer. Nesse momento, não foi apresentada nenhuma instrução adicional sobre o sistema de categorização propriamente dito.

O Observador 3 categorizou as respostas verbais do terapeuta, em 30 minutos de uma sessão terapêutica (Sessão 17). Foi realizado, então, um cálculo de concordância entre a categorização deste observador e a do pesquisador.
A seção Resultados apresenta os dados obtidos por meio dos testes preliminares de concordância (entre pesquisador e Observadores 1 e 2), a versão final do instrumento desenvolvido, o treino padronizado para observadores e os dados referentes à concordância entre pesquisador e Observador 3, obtidos a partir do treino.

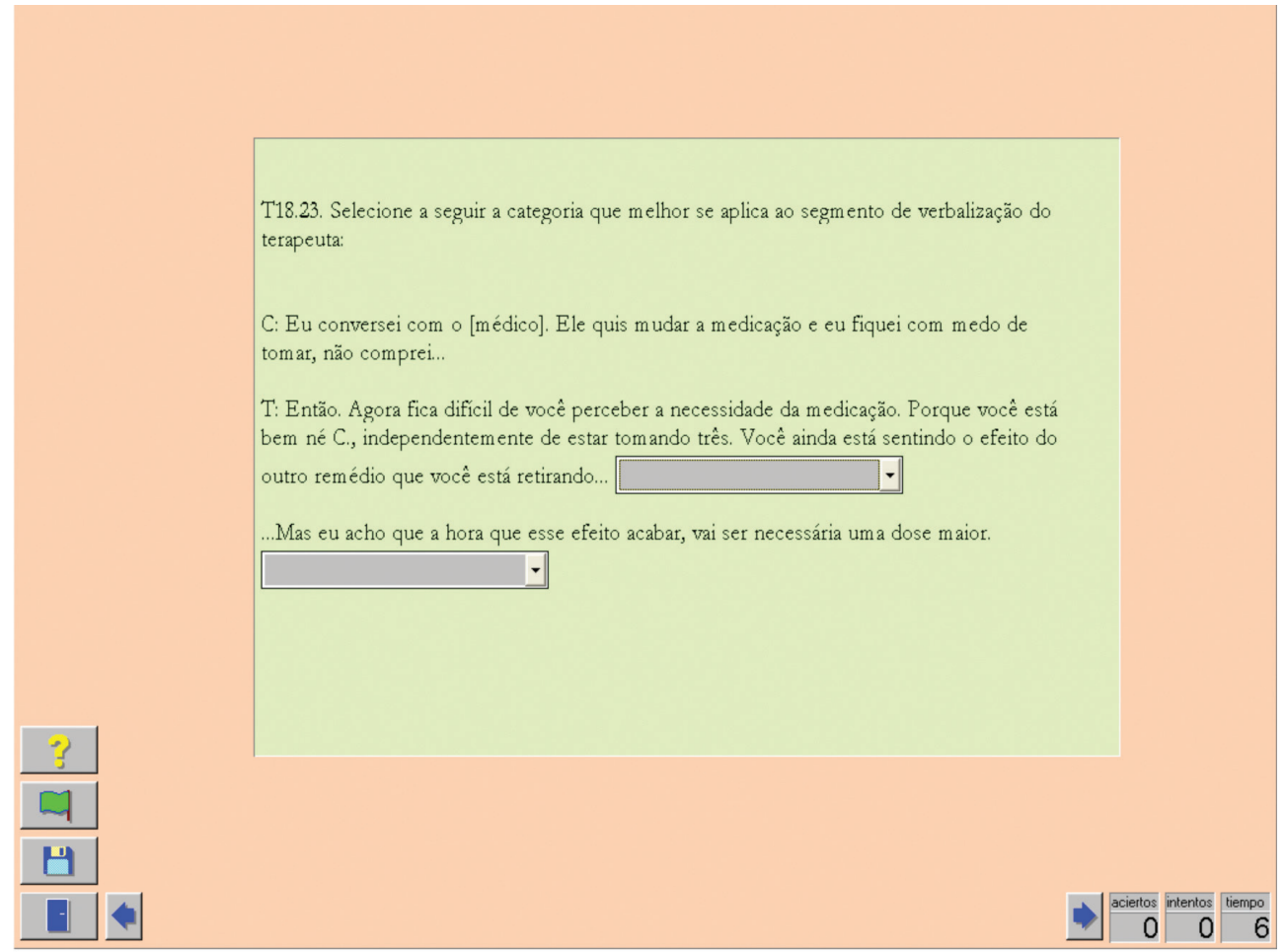

Figura 4. Exemplo de tela referente aos exercícios finais do treino do terapeuta.

\section{Resultados}

O sistema é composto por 16 categorias exaustivas e mutuamente excludentes, sendo que nove delas contemplam respostas verbais vocais, quatro referem-se a gestos comunicativos (respostas motoras cuja função é análoga à de respostas verbais vocais) e três categorias são residuais.

Cada categoria está organizada em torno dos seguintes elementos: (a) Nome da categoria: um rótulo que descreve em poucas palavras o essencial da categoria; (b) Sigla: duas ou três letras por meio das quais a categoria é identificada; (c) Nome resumido da categoria; (d) Definição: descrição detalhada das variáveis que devem controlar o pesquisador para a identificação do segmento da interação na referida categoria, com sugestões de subcategorias e exem- plos de trechos de interações terapêuticas relacionadas; (e) Caracterização geral da categoria: síntese dos elementos que a constituem, com comentários ao observador sobre o contexto típico no qual a classe de verbalizações ocorre; (f) Critérios de inclusão ou exclusão: critérios por meio dos quais a categoria é diferenciada de outras categorias que descrevem fenômenos semelhantes ${ }^{6}$. A Tabela 3 apresenta as 16 categorias do sistema.

6 No presente artigo, os critérios de inclusão e exclusão não serão apresentados e as definições das categorias são apresentadas de forma resumida. A versão completa das categorias encontra-se em Zamignani (2007). 


\section{Tabela 3}

Categorias Referentes ao Comportamento Verbal Vocal e Não Vocal do Terapeuta, do SiMCCIT

$\mathrm{T}=$ terapeuta $; \mathrm{C}=$ cliente.

\begin{tabular}{|c|c|c|c|}
\hline $\begin{array}{l}\text { Nome da categoria } \\
\text { (resumido) }\end{array}$ & Descrição resumida & Componentes & Exemplos \\
\hline $\begin{array}{l}\text { Terapeuta solicita relato } \\
\text { (SOLICITAÇÃO DE } \\
\text { RELATO) }\end{array}$ & $\begin{array}{l}\text { Verbalizações do terapeuta } \\
\text { nas quais ele solicita ao cliente } \\
\text { descrições a respeito de ações, } \\
\text { eventos, sentimentos ou pensa- } \\
\text { mentos. Ocorre tipicamente em } \\
\text { situações relacionadas à coleta } \\
\text { de dados e ao levantamento } \\
\text { de informações ao longo de } \\
\text { qualquer etapa do processo } \\
\text { terapêutico. }\end{array}$ & $\begin{array}{l}\text { - Solicitação de informa- } \\
\text { ções sobre fatos. } \\
\text { - Solicitação de relato de } \\
\text { respostas encobertas do } \\
\text { cliente. }\end{array}$ & $\begin{array}{l}\text { - T: Me conta... Por que é que você está procurando } \\
\text { terapia? } \\
\text { - T: Quando é que isso começou? } \\
\text { - T: Você consegue lembrar-se de um exemplo espe- } \\
\text { cífico no qual isso aconteceu? } \\
\text { - T: Em que momentos você tem se sentido assim? } \\
\text { - T: O que você teve vontade de fazer nessa hora? } \\
\text { - T: O que você pensou antes de fazer o ritual? }\end{array}$ \\
\hline $\begin{array}{l}\text { Terapeuta facilita o relato } \\
\text { do cliente (FACILITAÇÃO) }\end{array}$ & $\begin{array}{l}\text { Verbalizações curtas ou } \\
\text { expressões paralinguísticas } \\
\text { que ocorrem durante a fala } \\
\text { do cliente. Tipicamente, estas } \\
\text { verbalizações indicam atenção } \\
\text { ao relato do cliente e sugerem a } \\
\text { sua continuidade. }\end{array}$ & $\begin{array}{l}\text { - Verbalizações mínimas } \\
\text { - Expressões paralin- } \\
\text { guísticas. }\end{array}$ & $\begin{array}{l}\text { - T: Sei... } \\
\text { - T: Hum hum. }\end{array}$ \\
\hline $\begin{array}{l}\text { Terapeuta demonstra } \\
\text { empatia } \\
\text { (EMPATIA) }\end{array}$ & $\begin{array}{l}\text { Verbalizações do terapeuta que } \\
\text { sugerem acolhimento, aceitação, } \\
\text { cuidado, entendimento, valida- } \\
\text { ção da experiência ou sentimen- } \\
\text { to do cliente. Diferentemente } \\
\text { da categoria Aprovação, que } \\
\text { se refere a uma avaliação } \\
\text { sobre ações ou características } \\
\text { específicas do cliente, a Empatia } \\
\text { tem um caráter inespecífico, } \\
\text { informando essencialmente } \\
\text { que o cliente é aceito, "bem- } \\
\text {-vindo", sem implicar avaliação } \\
\text { ou julgamento. Essa classe de } \\
\text { verbalizações tem sido associa- } \\
\text { da tipicamente à criação de um } \\
\text { ambiente terapêutico amistoso, } \\
\text { seguro e não punitivo, para } \\
\text { que o cliente se sinta à vontade } \\
\text { para verbalizar eventos que, em } \\
\text { outros contextos, poderiam ser } \\
\text { alvo de punição. }\end{array}$ & $\begin{array}{l}\text { - Nomeação e inferência } \\
\text { de sentimentos. } \\
\text { - Normalizações e valida- } \\
\text { ção de sentimentos. } \\
\text { - Exclamações e expres- } \\
\text { sões de interesse. } \\
\text { - Verbalizações de } \\
\text { cuidado. } \\
\text { - Autorrevelações sobre } \\
\text { experiências similares. } \\
\text { - Validação de discor- } \\
\text { dâncias ou críticas do } \\
\text { cliente. } \\
\text { - Humor. } \\
\text { - Apoio. } \\
\text { - Paráfrases. } \\
\text { - Comentários de enten- } \\
\text { dimento. }\end{array}$ & $\begin{array}{l}\text { - T: Imagino o quanto isso te deixa ansioso. } \\
\text { - T: Essa tem sido uma parte crucial da sua vida, } \\
\text { né? } \\
\text { - T: Com tudo isso que está acontecendo, seria } \\
\text { estranho que você ficasse tranquilo, não é mesmo? } \\
\text { Acho natural que você tenha se sentido ansioso. } \\
\text { - C: Estou conversando com o P. todo dia por tele- } \\
\text { fone. Conheci pessoalmente. T: Olha só. } \\
\text { - T: Como é que você está? Na semana passada } \\
\text { você estava muito resfriada. } \\
\text { - T: Você sabe... eu também já passei por isso... é } \\
\text { muito chato quando a gente investe toda a energia } \\
\text { em um negócio e ele não dá certo... posso imaginar } \\
\text { o quanto você está frustrada. } \\
\text { - T: Eu gostaria muito de tê-lo ajudado para mudar } \\
\text { essa situação. Eu me pergunto o que poderia ter } \\
\text { sido diferente, mas o fato é que não foi possível e eu } \\
\text { também me sinto frustrado por isso. } \\
\text { - C: É, mas eu não dei o beijo que ele pediu. Falei: } \\
\text { "Imagina, estou dirigindo, olha o trânsito!". Nessas } \\
\text { alturas o trânsito ridículo, na Castelo, né? Mas eu } \\
\text { nem senti passar. T: Quanto mais trânsito melhor, } \\
\text { que você fica mais tempo com ele. [risos] } \\
\text { - T: Eu não sei qual será a sua decisão nesse caso, } \\
\text { mas qualquer que ela seja, eu estou do seu lado. } \\
\text { - T: E você perdeu seu emprego e está muito difícil } \\
\text { encontrar um outro. [resumindo a descrição do } \\
\text { cliente] } \\
\text { - C: Ela até nem colocou o meu, ela foi pegar um } \\
\text { dela, amarelo, assim. T: Todo mundo ajudando! }\end{array}$ \\
\hline
\end{tabular}


Terapeuta fornece informações (INFORMAÇÃO)

Terapeuta solicita reflexão (SOLICITAÇÃO DE REFLEXÃO)

Terapeuta recomenda ou solicita a execução de ações, tarefas ou técnicas (RECOMENDAÇÃO)
Verbalizações nas quais o terapeuta relata eventos ou informa o cliente sobre eventos (que não o comportamento do cliente ou de terceiros), estabelecendo ou não relações causais ou explicativas entre eles. Essa classe de verbalizações é tipicamente associada a intervenções "psicoeducacionais" e ao "enquadre" ou contrato terapêutico.

Verbalizações nas quais o terapeuta solicita ao cliente qualificações, explicações, interpretações, análises ou previsões a respeito de qualquer tipo de evento. Diferentemente de Solicitação de Relato, na qual o terapeuta pede que o cliente apenas relate a ocorrência de eventos, sentimentos ou pensamentos, nesse caso o terapeuta solicita que o cliente analise ou estabeleça relações entre os eventos em discussão. Em sessões de terapia analítico-comportamental, essa classe de verbalizações ocorre tipicamente quando o terapeuta busca facilitar o estabelecimento de relações funcionais e a formação de autorregras.

Sugestão de alternativas de ação ou solicitação de que cliente se engaje em ações ou tarefas. Recomendação contempla verbalizações nas quais o terapeuta sugere alternativas de ação ao cliente ou solicita o seu engajamento em ações ou tarefas. Deve ser utilizada quando o terapeuta especifica a resposta a ser (ou não) emitida pelo cliente. A literatura refere-se a essa classe de comportamentos também como aconselhamento, orientação, comando, ordem.

- Informações factuais.

Explicações.

- Descrição de regularidades ou padrões recorrentes.

- Explicações teóricas e experimentais.

- Informações sobre o contrato terapêutico.

- Descrição de estratégias, de procedimentos ou do programa terapêutico.

- Justificativas de intervenções.

- Solicitação de análise. - Solicitação de avaliação.

- Solicitação de previsão.

- Solicitação de obser-

vação.

\section{- Conselhos.}

- Modelo.

- Incentivo.

- Estruturação de atividade.

- Permissão, proibição ou solicitação de parada.
- T: Biologia requer vários cursos adicionais de laboratório.

- C: Você conhece o psiquiatra X? T: Não. Não conheço um médico com esse nome.

- C: Você já atendeu casos como esse? T: Sim, muitos.

- T: Um ataque de pânico pode ocorrer independentemente de a pessoa ter síndrome do pânico.

- T: Nós nos encontraremos duas vezes por semana. - T: Vamos falar sobre a última semana primeiro, depois nós vamos falar um pouco mais sobre a sua situação em casa.

- T: O valor da sessão é \$\$.

- T: Durante a exposição, nós vamos trazer para a sessão algo que você teme e você deverá permanecer em contato com ele sem fazer o ritual.

- T: Eu não gosto desse tipo de procedimento, mas é o único que vai te ajudar nesse momento.

T: Gostaria que você pensasse nessa semana sobre o que conversamos hoje, sobre os benefícios que você obtém quando se queixa dessa maneira com sua família.

$\mathrm{T}$ : Você tem alguma hipótese de por que isso aconteceu?

T: Você está me dizendo que todos os seus namorados agem com você de forma muito semelhante ao seu pai. Você acha que isso é apenas uma coincidência?

$\mathrm{T}$ : O que você achou da reação dele?

T: Você acha correta a forma como ele agiu?

T: Tendo em vista os últimos acontecimentos, você pode imaginar como será a próxima tentativa dele? T: E agora, o que você acha que vai acontecer?

T: Eu gostaria que você registrasse as situações que te provocam ansiedade, para que possamos discutir na semana que vem.

T: Vamos fazer uma coisa: eu quero que você anote em um caderninho o que você comeu em cada refeição, a que horas você comeu e se aconteceu algo relevante naquele dia ou logo antes de você comer.

$\mathrm{T}$ : Tente conversar com seu pai durante a semana e Ihe falar sobre o que você sente nessas situações.

$\mathrm{T}$ : Você deveria cuidar de sua vida e deixar que seu irmão administre as suas próprias coisas.

T: Agora me diga o mesmo que você acabou de dizer, só que sem mexer as pernas.

T: Você não deve se sentir culpado por uma coisa que não foi sua responsabilidade. Lembre-se que nem tudo está sob seu controle.

T: Quando você for enfrentar a situação, lembre-se de todas as vezes que você teve sucesso.

$\mathrm{T}$ : Tente repetir a sequência do jogo assim como eu fiz.

T: Eu vou falar como eu acredito que você deveria conversar com o seu chefe.

T: Tenho certeza que você é capaz de fazer isso.

T: Agora vamos fazer um exercício de exposição: experimente pegar na maçaneta dessa porta e ficar por 15 minutos sem lavar as mãos.

T: Esse assunto é bastante importante. Vamos voltar a falar sobre ele na próxima sessão.

C: Eu posso anotar tudo à noite, antes de dormir, ou tenho que fazer na hora em que acontece? T: Faça como você achar melhor. $\mathrm{O}$ importante é que você registre o máximo de situações que ocorrerem ao longo do dia.

T: Eu gostaria que você não colocasse os pés no sofá. 
Terapeuta interpreta (INTERPRETAÇÃO)
Terapeuta aprova ou concorda com ações ou avaliações do cliente (APROVAÇÃO)
Verbalizações nas quais o terapeuta descreve, supõe ou infere relações causais e/ou explicativas (funcionais, correlacionais ou de contiguidade) a respeito do comportamento do cliente ou de terceiros, ou identifica padrões de interação do cliente e/ou de terceiros* ${ }^{*}$ Na literatura clínica analítico-comportamental, a análise de contingências ou a análise funcional apresentada pelo terapeuta envolve, em parte, essa classe de verbalizações.

$\left({ }^{*}\right)$ Este critério diferencia esta categoria de Informação que, por sua vez, contém explicações a respeito de outros eventos que não o comportamento do cliente e/ou de terceiros.
- Descrições de relações explicativas entre ações (do cliente e/ou de terceiros) e outros eventos - Descrição de regularidades ou padrões recorrentes entre ações (do cliente e/ou de terceiros) e outros eventos ou ações.

- Diagnóstico.

- Devolutiva de avaliação padronizada.

- Estabelecimento de sínteses.

- Metáforas ou analogias explicativas.

- Inferências.

- Previsões.

- Confrontações.

- Descrição de processo.

T: Talvez o seu problema não seja de motivação, mas que até agora as coisas ainda não deram certo. T: Você se cobra em melhorar o desempenho sexual com seu marido mas, da maneira como você descreve a relação sexual, ela não é satisfatória para você. $\mathrm{T}$ : A impressão que eu tenho é que sempre que ele te faz um elogio, ele é seguido por uma crítica, do tipo "Você foi ótimo na apresentação, mas...".

T: Essa é uma dúvida que te persegue, né? Se é por você ou pela gravidez que ele está mudando.

T: Você se dá conta de que as suas obsessões sempre são relacionadas a situações nas quais você age por impulso com outras pessoas e depois se arrepende? Aí você fica ruminando sobre o que poderia ter sido diferente.

$\mathrm{T}$ : Você parece mais ansioso que deprimido T: Isso que você acabou de descrever é conhecido pela psiquiatria como Transtorno ObsessivoCompulsivo.

$\mathrm{T}$ : $\mathrm{O}$ teste indica que você tem maior interesse por profissões relacionadas ao cuidado e atendimento de pessoas.

T: Então, você está dependente de álcool. Já deve estar começando a beber de manhã, eu suponho. T: Quando você falou que tinha dor de cabeça, eu me lembrei daquelas mulheres que na hora de transar dizem "Ah, eu não posso, estou com dor de cabeça".

T: Imagino que ele tenha sido extremamente gentil nas primeiras semanas e depois...

T: Acredito que a próxima coisa que ele vai fazer é te convidar para sair.

T: Você estava dizendo há pouco que o seu marido não lhe dá a menor atenção, mas agora você está me dizendo uma série de cuidados que ele tem com você.

C: Porque às vezes as coisas empacam, entendeu? T: É, eu sei, e não é de hoje, né? Não é de hoje a coisa vem e vai piorando, piorando. Não sei, acho até que hoje você convive melhor.

Aprovação contempla verbalizações do terapeuta que sugerem avaliação ou julgamento favoráveis a respeito de ações, pensamentos, características ou avaliações do cliente. Verbalizações de Aprovação dirigem-se a ações ou características específicas do cliente e pressupõem o terapeuta como alguém que pode selecionar e fortalecer aspectos de seu comportamento que seriam mais ou menos apropriados. Isso difere da categoria Empatia, que tem um caráter inespecífico e não envolve avaliação ou julgamento.
- Elogios ou avaliações positivas sobre o cliente. - Descrição de ganhos terapêuticos.

- Verbalizações de concordância.

-Pseudodiscordância.

- Relato de sentimentos positivos.

Exclamações e expressões de aprovação. - Agradecimentos.
T: Você tomou a decisão certa. Está lidando com isso muito bem!

T: Que lindo esse teu colarzinho!

T: Puxa, eu estava me lembrando da época em que a gente começou a trabalhar juntos. Como as coisas estão mudadas! Você lembra que era difícil para você até mesmo vir sozinha para cá? E agora você está se virando sozinha, com o maior desprendimento. Acho muito legal isso!

T: Com certeza! Você tem toda a razão.

C: Eu só melhorei por causa da medicação. T: De fato, a medicação pode te ajudar, mas se você não tivesse agido, tudo estaria igual.

T: Gostei muito da nossa sessão de hoje. Acho que falamos de assuntos bastante importantes.

T: Você conversa super bem! É muito agradável conversar com você.

C: Consegui recuperar a minha nota de matemática. T: Que máximo!

C: Não, você é uma das responsáveis. Você, está sabendo me conduzir, porque eu estou tendo mais discernimento, estou tentando encontrar o caminho. T: Que bom, obrigada, fico muito contente. 
Terapeuta reprova ou discorda de ações ou avaliações do cliente (REPROVAÇÃO)
Outras verbalizações do terapeuta (OUTRAS VOCAL TERAPEUTA)
Avaliação ou julgamento desfavorável. Reprovação contempla verbalizações do terapeuta que sugerem avaliação ou julgamento desfavoráveis a respeito de ações, pensamentos, características ou avaliações do cliente. Assim como Aprovação verbalizações de Reprovação dirigem-se a ações ou características específicas do cliente e pressupõem o terapeuta como alguém que pode selecionar aspectos de seu comportamento que seriam mais ou menos apropriados. Reprovação tem sido frequentemente associada na literatura clínica, a interações aversivas em psicoterapia, que podem ameaçar a manutenção da relação terapêutica.
Verbalizações do terapeuta não classificáveis nas categorias anteriores.
- Discordância.

- Crítica.

- Ironia.

- Ameaça.

- Autorrevelações desa-

fiadoras.

- Relato de sentimentos negativos.

- Verbalizações do terapeuta não classificáveis nas categorias anteriores.

- Acertos ocasionais.

- Recuperação de assunto.

- Opiniões pessoais sobre eventos externos.
T: Eu não acho que seja assim.

T: As coisas são muito mais simples do que você pinta.

T: Eu penso que você faz bem algumas coisas, tais como supervisionar, monitorar [APR], mas às vezes você entra em uma escalada de castigo, castigo, castigo. [REP]

T: Você de fato pensa que sua mãe deveria deixá-lo vir para casa quando você quer?

T: Eu vou pegar uma xícara de café. Eu estou perdido.

T: Eu acho que a gente faz escolhas. Você pode continuar fugindo de escolher uma profissão... há tantas pessoas que preferem ser donas de casa e lavar as roupas do marido o resto da vida.

T: Você quer dizer que você o deixa dormir em sua cama e ele a molha toda noite? [risada]

T: Quando eu resolvi sair da casa de meus pais, eu tinha plena consciência de que eu deveria me sustentar, e não ficar esperando que meus pais me ajudassem.

T: Eu vou continuar a atendê-lo porque para mim é um desafio, mas eu não gostei de você.

T: Eu fico muito irritado quando você fala comigo dessa forma e, quando isso acontece, a vontade que eu tenho é de te tratar da mesma forma.

T: Eu quero ajudá-la, mas é impossível fazermos alguma coisa com tantos atrasos. O que nós podemos fazer em 10 minutos de sessão?

T: Aceita uma balinha?

T: Só um minutinho, que eu vou pedir uma água para a secretária.

T: Desculpe, eu me esqueci de desligar o celular.

T: Então, a gente, na semana que vem, faz a sessão na terça-feira, das $15 \mathrm{~h}$ às $16 \mathrm{~h}$.

C: Onde é que eu estava mesmo? T: Você estava falando sobre sua viagem de férias.

T [após interrupção da sessão] Então, você estava me falando sobre o seu receio de prestar o vestibular.

C: Eu fiquei realmente chocado com aquela cena T: Eu acho que a televisão não deveria mostrar esse tipo de coisa. Não acrescenta nada à vida das pessoas.

Não exemplo: T: Eu penso que você poderia, sim, ter comprado o livro. Afinal, o dinheiro é seu, não é? [REC]

Não é uma verbalização do tipo opiniões pessoais sobre eventos externos porque se refere ao comportamento do cliente.
Terapeuta permanece em silêncio (SILÊNCIO TERAPEUTA)
Esta categoria deve ser selecionada quando uma resposta verbal do terapeuta é encerrada sem que uma nova resposta verbal do mesmo falante seja iniciada.

Respostas verbais não vocais: categorias a serem utilizadas apenas em caso de dados registrados em vídeo; do contrário, essas categorias podem ser suprimidas do sistema.

Entende-se por comunicação não vocal respostas motoras, gestos ou expressões faciais que são substitutas comuns de verbalizações, isto é, ações cujos significados são compartilhados entre emissor e receptor. Gestos comunicativos e expressões faciais são considerados como comunicação não vocal apenas quando ocorrem na ausência de qualquer verbalização, nitidamente como signos da interação terapeuta-cliente. São classificados por meio das categorias a seguir, com função análoga à de seus correspondentes verbais. 
Respostas não vocais de facilitação/ concordância (CONCORDÂNCIA TERAPEUTA

Gestos ou expressões faciais do terapeuta relacionados à concordância, aprovação, compreensão com relação à fala do interlocutor e que ocorrerem nitidamente como signos da interação terapeuta-cliente.
Respostas não vocais de discordância (DISCORDÂNCIA TERAPEUTA)
Gestos ou expressões faciais do terapeuta relacionados à oposição, discordância, descrença ou reprovação com relação a uma verbalização ou ação do interlocutor e que ocorrem nitidamente como signos da interação terapeuta-cliente
- Meneios com a cabeça: fazer que "sim" com a cabeça, sugerindo concordância, interesse no assunto ou ação do interlocutor e/ou solicitando a continuidade da fala do interlocutor.

- Gestos de aprovação: consistem, por exemplo, em levantar o polegar enquanto os outros dedos permanecem fechados (e.g., "jóia", "ok").

- Gestos ou expressões faciais de aprovação, concordantes.

- Gestos ou expressões que concordam com o relato do outro falante ou que sugerem cuidado/acolhimento.

- Gestos ou expressões faciais de negação ou preocupação: gestos ou expressões de negação ou preocupação, mas que sugerem concordância com relação a uma verbalização do interlocutor ou cuidado/acolhimento.

- Balançar a cabeça lateralmente: fazer que "não" com a cabeça, sugerindo discordância, descrença, reprovação com relação à fala ou à ação do interlocutor. - Gesto com as mãos: gestos que indicam reprovação, discordância ou descrença com relação à fala ou à ação do cliente.

- Gestos ou expressões faciais de reprovação, negação ou preocupação: gestos ou expressões que sugerem discordância, descrença, reprovação com relação à fala ou à ação do interlocutor.
Respostas não vocais de pedido, ordem, comando, incentivo (COMANDO TERAPEUTA
Gestos ou expressões faciais do terapeuta relacionados a pedido, ordem ou incentivo, ou que sugerem algum tipo de contenção do cliente, ordenação ou organização do ambiente da sessão. Devem ocorrer nitidamente como signos da interação terapeuta-cliente.
- Qualquer gesto com as mãos ou a cabeça apontando ou indicando algum objeto ou evento: sugerindo que o cliente olhe em direção, pegue o objeto ou se dirija ao ponto indicado.

- Gestos com as mãos espalmadas: gestos com a palma da mão dirigida ao interlocutor, sugerindo ordem de parada ou interrupção da verbalização ou ação em curso.

- Gestos ou expressões de pedido, ordem, comando ou incentivo: gestos ou expressões faciais que sugerem pedido, ordem, comando ou incentivo com relação à ação ou à verbalização do cliente.
Outras respostas não vocais (GESTO OUTROS TERAPEUTA)

Registro insuficiente (INSUFICIENTE TERAPEUTA)
Gestos não contemplados nas categorias anteriores.

Qualquer ação do terapeuta cuja identificação está impossibilitada devido a problemas no registro em áudio ou vídeo.
- Respostas motoras, gestos ou expressões faciais do terapeuta que ocorrem na ausência de qualquer verbalização, cujo significado não é contemplado nas categorias anteriores. Devem ocorrer nitidamente como signos da interação terapeuta-cliente.
- Verbalizações são categorizadas como Insuficiente Terapeuta apenas quando não podem ser identificadas mesmo depois de observadas por três vezes. Falas interrompidas do terapeuta, cujo conteúdo identificável não é suficiente para a categorização em uma das categorias anteriores, são classificadas como Insuficiente Terapeuta.
Após o desenvolvimento do treino de observadores, o Observador 3 foi a ele submetido e orientado para o manuseio do software The Observer. $\mathrm{Na}$ sequência, ele categorizou as respostas verbais do terapeuta e do cliente, com seus respectivos qualificadores, em 30 minutos de uma sessão terapêutica (Sessão 17). Os dados de concordância entre a categorização do Observador 3 e a do pesquisador encontram-se na Tabela 4.

\section{Tabela 4}

Valores Obtidos no Cálculo de Concordância entre o Observador 3 e o Pesquisador, Referentes às Categorias de Respostas Verbais do Terapeuta, na Categorização Final de 30 Minutos da Sessão 17

\section{Sessão 17: Dados referentes ao comportamento verbal do terapeuta}

\begin{tabular}{ll}
\hline Medida & Valor \\
\hline Duração (segundos) de concordâncias & 1749,07 \\
Duração (segundos) de discordâncias & 50,93 \\
Percentual de concordância & 97,17 \\
Índice de concordância & 0,97 \\
Coeficiente Kappa & 0,84
\end{tabular}


Como se vê, a Tabela 4 mostra altos índices de concordância entre observadores com relação às categorias do terapeuta. Uma vez que o Observador 3 efetuou a categorização baseado unicamente no treino de observadores (e na consulta eventual ao manual), pode-se considerar que o treino (acompanhado do manual) cumpriu adequadamente a sua função, assim como as categorias e definições foram suficientemente precisas.

\section{Discussão}

A escolha por aprofundar o estudo sobre a categorização de eventos e, mesmo, desenvolver um novo sistema, tem como origem a identificação de algumas inconsistências encontradas na literatura de pesquisa - nacional e estrangeira. Essas inconsistências dizem respeito especialmente à grande diversidade de categorias e de definições utilizadas, à ausência de sistemas que englobassem comportamentos não vocais e à reduzida aplicabilidade de parte dos sistemas até então desenvolvidos para o estudo da terapia analítico-comportamental.

Algumas características desta modalidade de terapia consideradas na elaboração do sistema foram: (a) a ênfase nas consequências do comportamento dentro da sessão terapêutica - daí a proposta em se diferenciar os tipos de "feedback" fornecidos pelo terapeuta enquanto Facilitação, Empatia, Aprovação e Reprovação; (b) a coexistência na literatura da abordagem de propostas terapêuticas de cunho prescritivo - contempladas nas categorias Informação, Recomendação, Aprovação e Reprovação - e reflexivo - contempladas no sistema por meio das categorias Solicitação de Reflexão e Interpretação; (c) a importância atribuída à relação terapêutica na condução da intervenção dentro da abordagem - tendo nas categorias Facilitação, Empatia, Aprovação e Reprovação, bem como em algumas categorias não vocais, alguns indicadores de seu estabelecimento ou manutenção.

A construção do presente sistema de categorização teve como ponto de partida uma extensiva análise da literatura em diferentes campos, incluindo um estudo das pesquisas clínicas até então desenvolvidas, da literatura para a formação de terapeutas analítico-comportamentais e de textos de metodologia para o desenvolvimento de instrumentos de observação. Além desse levanta- mento bibliográfico, desenvolveu-se uma análise dos sistemas de categorização existentes, visando à identificação de elementos relevantes da interação terapêutica.

Além de ter como base outros sistemas já estudados, a construção do sistema de categorização foi pautada em repetidas tentativas de categorização de sessões terapêuticas - transcrições de sessões utilizadas em trabalhos anteriores, além de sessões registradas em vídeo especialmente para o presente trabalho. Durante processo de elaboração do sistema, ocorreram diversas consultas a grupos de pesquisadores que acompanharam e discutiram os critérios de categorização envolvidos. Considerando todos estes aspectos, pode-se afirmar que a primeira etapa (i.e., consolidação de uma base teórico-clínica) proposta por Rice e Kerr (1986) foi cumprida.

Quanto às definições elaboradas, especificou-se cada elemento que compõe as categorias, com sugestões de rótulos de subcategorias (caso haja interesse do pesquisador), além de vários exemplos para cada uma delas (cabe lembrar que não foi parte da proposta do trabalho de Zamignani, 2007, estabelecer subcategorias mutuamente exclusivas, não tendo havido nenhum teste neste sentido). Quanto ao caráter descritivo do instrumento, houve um cuidado em estabelecer categorias que exigissem o mínimo de inferência. Embora as categorias propostas não sejam de natureza exclusivamente topográfica, sua definição estabelece uma série de critérios formais que orientam a sua identificação. Pode-se afirmar que a segunda etapa (i.e., especificação dos elementos por meio dos quais os comportamentos em cada classe podem ser reconhecidos) proposta por Rice e Kerr (1986) também foi cumprida.

O estudo de concordância entre observadores referente ao Sistema de Categorias Verbais do Terapeuta foi conduzido, obtendo-se dados bastante consistentes, com alto grau de concordância entre os diferentes observadores, tendo sido o critério cumprido. Este dado, entretanto, não dispensa a necessidade de novos estudos de concordância com outros conjuntos de sessões. A criação de um extenso treino sistemático se mostrou um empreendimento proveitoso, na medida em que produziu um bom índice de concordância nas categorias do terapeuta entre o pesquisador e o Observador 3 - o qual havia sido exposto unicamente ao treino siste- 
mático. Vale ressaltar a necessidade de novas verificações de concordância, especialmente um teste em que ambos os observadores sejam treinados exclusivamente pelo software de treino.

Houve uma preocupação no trabalho de Zamignani (2007) de se aplicar o conjunto de categorias desenvolvidas a diferentes sessões terapêuticas, o que foi feito desde as etapas iniciais, no estudo de sessões de atendimento em pesquisas previamente desenvolvidas até a categorização efetuada no desenvolvimento do trabalho propriamente dito. É importante acrescentar que, embora não tenha sido objeto do presente artigo, o trabalho de Zamignani (2007) incluiu um estudo de aplicação das categorias a um conjunto de sessões terapêuticas. Além disso, vários trabalhos investigaram sessões terapêuticas utilizando a versão preliminar ou a versão definitiva do sistema de categorias para as respostas verbais vocais do terapeuta (Amaral, 2010; Araldi \& Martins, 2005; Baldivia \& Souza, 2005; Barros \& Bistocchi, 2006; Carvalho \& Henrique, 2005; Donadone, 2009; Kameyama, 2011; Lima \& Lopes, 2006; Oshiro, 2011; Pinto, 2007; Rocha, 2008; Rossi, 2011; Rubba \& Leite, 2006; Sadi, 2010; Xavier, 2010).

Outros autores ainda adaptaram as categorias do sistema para o estudo de diferentes modalidades de sessões terapêuticas, tais como terapia analítico-comportamental infantil (Del Prette, 2006), grupo psicoeducacional (Silveira, 2007) e terapia analítico-comportamental de casal (Marques, 2009). Os dados obtidos por meio de tais estudos foram utilizados para o aperfeiçoamento do sistema de categorização, além de evidenciarem a adequação do sistema para o estudo de diferentes questões de pesquisa clínica, o que fornece algumas evidências de validade aparente $e^{7}$ das categorias desenvolvidas no presente trabalho. É importante considerar, entretanto, que mais estudos são necessários para demonstrar sua aplicabilidade a diferentes modalidades de intervenção, o que eventualmente pode levar a seu aperfeiçoamento. Também é necessário um estudo mais detalhado das subcategorias propostas, com vistas a uma descrição mais precisa de

7 O termo validade aparente diz respeito à extensão à qual o sistema de observação parece medir o que ele se propõe a medir (Suen \& Ary, 1989). cada uma delas e ao desenvolvimento de eventuais critérios de diferenciação entre elas. Isso porque o uso das subcategorias pode ser necessário para o estudo de algumas questões de pesquisa.

Outra evidência de validade do presente instrumento advém de seu processo de construção. De modo semelhante ao caminho traçado por Hill (1986), o desenvolvimento deste sistema de categorização baseou-se no estudo cuidadoso de outros sistemas, cujas categorias foram posteriormente reorganizadas em um novo esquema. Este processo, segundo a autora, assegura um tipo de validade de conteúdo. É importante lembrar que tais evidências não são suficientes para se estabelecer com segurança a validade do instrumento, mas elas se somam neste sentido, e evidências provenientes de novos estudos podem fortalecer este indicador de validade. Novos estudos podem seguir a recomendação de Rice e Kerr (1986), de que a categorização seja associada a resultados do processo.

Em um artigo de revisão da área de pesquisas de processo em psicoterapia, Greenberg e Pinsof (1986) afirmam que a falta de uma "microteoria da psicoterapia" teria retardado o desenvolvimento da pesquisa na área. Esta teoria, segundo os autores, deveria ser suficientemente clara, de modo a especificar o que deve ocorrer e quando, nas diferentes etapas de seu desenvolvimento, além de explicitar as relações entre os diferentes processos que ocorrem em pontos específicos, dentro e fora da sessão terapêutica. Essa microteoria seria a base na qual os pesquisadores buscariam apoio para especificar quando e para onde olhar no curso da terapia, o que favoreceria a identificação de padrões de mudança que ocorrem ao longo do processo terapêutico.

O SiMCCIT foi elaborado visando ao estudo da interação na terapia analítico-comportamental. Sessões dessa modalidade de psicoterapia foram a base para a organização do sistema e para a elaboração das definições de categorias nele contidas. Um exercício de aplicação de categoria às diferentes etapas do processo terapêutico analítico-comportamental foi conduzido no trabalho de Zamignani (2007). As categorias desenvolvidas mostraram-se úteis para a descrição dos padrões de interação que ocorrem em diferentes momentos do processo terapêutico. Nas sessões iniciais, são identificados comportamentos relacionados à coleta de dados (cate- 
gorias Solicitação de Relato, Solicitação de Reflexão e Facilitação), ao estabelecimento do contrato (Informação) e à devolutiva inicial (Interpretação e Informação). Comportamentos relacionados à relação terapêutica e ao estabelecimento da aliança terapêutica são identificados nas categorias Empatia, Facilitação e Aprovação, enquanto eventos que podem colocar em risco tal relação são identificados principalmente na categoria Reprovação, mas também em outras categorias, a depender da sequência de eventos.

O sistema prevê também a detecção de comportamentos do terapeuta envolvidos em diferentes modelos de intervenção que podem ser característicos da terapia analítico-comportamental. Intervenções diretivas são identificadas nas categorias Recomendação, Informação, Aprovação e Reprovação, ao passo que as categorias Solicitação de Reflexão e Interpretação são mais características de intervenções reflexivas. As categorias não vocais foram elaboradas tendo em vista ações típicas do processo terapêutico que não são acompanhadas de respostas vocais (gestos de Aprovação, Reprovação e Comando). O sistema conta ainda com categorias residuais que podem ser utilizadas no caso de trecho do registro incompreensível (Registro Insuficiente) ou de comportamentos não contemplados nas outras categorias (Outras Terapeuta).

O SiMCCIT foi aplicado no presente estudo por meio do software The Observer, que permite a categorização a partir dos dados em vídeo. Entretanto, o sistema já foi aplicado em trabalhos que utilizaram a transcrição de sessões - nesse caso, suprimindo ou incluindo notas de transcrição referentes às categorias não vocais (e.g., Del Prette, 2006) e folhas de registro com intervalo de tempo (Amaral, 2010). Em ambos os casos, a utilização do sistema se mostrou viável.

Nas últimas décadas, muitos autores (e.g., Dougher, 1999; Hayes, 1987; Kohlenberg \& Tsai, 1991; Pérez Álvarez, 1996) avançaram no desenvolvimento de uma descrição dos processos que ocorrem na terapia de base analítico-comportamental, especialmente no que se refere à interação terapeuta-cliente em terapia verbal ${ }^{8}$. O sistema aqui apre-

8 Grande parte da interação que ocorre em psicoterapia é eminentemente verbal (Pérez Álvares, 1996) e a investigação sentado visa a contribuir para o desenvolvimento dessa área, permitindo a comparação entre dados de diferentes pesquisas e, a partir de uma massa de dados mais robusta, a identificação de padrões mais sutis, de difícil detecção com conjuntos menores de dados. Apesar da ênfase em processos da terapia analítico-comportamental, acredita-se que os fenômenos destacados nas categorias que compõem o SiMCCIT também possam ser identificados em terapias de outras abordagens, talvez com maior ou menor ênfase em algumas classes de comportamento.

Merece ainda consideração a possibilidade de utilização do SiMCCIT para o ensino de habilidades básicas do terapeuta. $\mathrm{O}$ seu processo de construção tinha em vista apenas a descrição do processo terapêutico para a pesquisa (e, portanto, não visava ao desenvolvimento de categorias prescritivas, destinadas à formação de terapeutas). Entretanto, a própria organização do sistema de categorias destaca os eventos relevantes em terapia analítico-comportamental, o que tem permitido o uso do software de treino de observadores como material didático auxiliar no ensino de terapeutas analítico-comportamentais.

Acreditamos que o SiMCCIT, por sua descrição minuciosa de comportamentos do terapeuta que ocorrem na interação terapêutica, por ter sido construído a partir de um amplo levantamento de comportamentos da sessão terapêutica e por oferecer ao pesquisador um catálogo amplo e de fácil utilização para o estudo de diferentes questões do processo terapêutico, pode preencher uma importante lacuna metodológica no desenvolvimento das pesquisas de processo no Brasil.

\section{Referências}

Almásy, C. (2004). Efeitos da consequência na sessão terapêutica. Dissertação de mestrado. Pontifícia Universidade Católica de São Paulo.

Amaral, S. S. (2010). Efeitos da solicitação e de subsequente descrição dos relatos verbais de um terapeuta sobre seu desempenho em sessões pos-

do processo terapêutico necessariamente deve passar por uma compreensão dos processos

verbais e de sua interação com eventos não verbais que ocorrem ao longo da terapia. 
teriores (Dissertação de mestrado). Pontifícia Universidade Católica de São Paulo, São Paulo. Araldi, S., \& Martins, T. C. (2005). A interação verbal terapeuta-cliente: Categorização e análise da fala de terapeutas formandos e recém formados (Trabalho de conclusão de curso). Universidade São Judas Tadeu, São Paulo

Baldivia, F. M., \& Souza, M. V. (2005). A avaliação da sessão terapêutica e sua relação com as intervenções do terapeuta (Trabalho de conclusão de curso). Universidade São Judas Tadeu, São Paulo.

Baptistussi, M. C. (2001). Comportamentos do terapeuta na sessão que favorecem a redução de efeitos supressivos sobre comportamentos punidos do cliente (Dissertação de mestrado).Pontifícia Universidade Católica de São Paulo, São Paulo.

Barbosa, D. R. (2001) Relação entre mudanças de peso e competência social em dois adolescentes obesos durante intervenção clínica comportamental (Dissertação de mestrado). Universidade de São Paulo, São Paulo.

Barbosa, J. I. C. (2006). Análise das funções de verbalizações de terapeuta e cliente sobre sentimentos, emoções e estados motivacionais na terapia analítico-comportamental (Tese de doutorado). Universidade Federal do Pará, Belém.

Barros, A. R., \& Bistocchi, A. (2006). A fala do cliente em diferentes abordagens: Categorização e análise das relações funcionais (Trabalho de conclusão de curso). Universidade São Judas Tadeu, São Paulo.

Bischoff, M. M., \& Tracey, T. J. G. (1995). Client resistance as predicted by therapist behavior: A study of sequential dependence. Journal of Counseling Psychology, 42, 487-495.

Brandão, F. S. (2003). O manejo das emoções por terapeutas comportamentais. (Dissertação de mestrado). Universidade de São Paulo, São Paulo.

Britto, I. G. S., Oliveira, J. A., \& Sousa, L. F. D. (2003). A relação terapêutica evidenciada através do método de observação direta. Revista Brasileira de Terapia Comportamental e Cognitiva, 5(2), 139-149.

Caballo, V. E. (1993). Manual de evaluación y entrenamiento de las habilidades sociales. Madrid: Siglo Veintiuno de España Editores S.A.
Carvalho, A., \& Henrique, C. T. (2005). As intervenções do terapeuta e sua relação com os estados internos relatados pelo cliente e terapeuta (Trabalho de conclusão de curso). Universidade São Judas Tadeu, São Paulo.

Chamberlain, P., \& Ray, J. (1988). The therapy process code: A multidimensional system for observing therapist interactions in family treatment. Em R. J. Prinz (Ed.), Advances in behavioral assessment of children and families (pp. 189-217). Greenwich: JAI.

Chamberlain, P., Patterson, G., Reid, J., Kanavagh, K., \& Forgatch, M. (1984). Observation of client resistance. Behavior Therapy, 15, 144-155.

Cronbach, L. J., \& Meehl, P. E. (1955). Construct validity in psychological tests. Psychological Bulletim, 52, 281-302.

Cunha, W. H. A. (1975). Alguns princípios de categorização, descrição e análise do comportamento. Ciência e Cultura, 28(1), 15-24.

Danna, M. F., \& Matos, M. A. (1999). Ensinando observação: Uma introdução. São Paulo: Edicon.

Del Prette G. (2006). Terapia analítico-comportamental infantil: Relações entre o brincar e comportamentos da terapeuta e da criança (Dissertação de mestrado). Universidade de São Paulo, São Paulo.

Donadone, J. C. (2004). O uso da orientação em intervenções clínicas por terapeutas comportamentais experientes e pouco experientes (Dissertação de mestrado). Universidade de São Paulo, São Paulo.

Donadone, J. C. (2009). Análise de contingências de orientações e auto-orientações em intervenções clínicas comportamentais (Tese de doutorado). Universidade de São Paulo, São Paulo.

Dougher, M. J. (1999). Clinical Behavior Analysis. Reno, Nevada: Context Press.

Fagundes, A. J. F. M. (1992). Descrição, definição e registro de comportamento. São Paulo: Edicon. (Trabalho original publicado em 1976)

Fiorini, H. J. (1995). Teorias e Técnicas de Psicoterapia. Rio de Janeiro: Francisco Alves.

Ford, J. D. (1978). Therapeutic relationship in behavior therapy: An empirical analysis. Journal of Consulting and Clinical Psychology, 46(6), 13021314. 
Garcia, M. R. (2001). Uma tentativa de identificação de respostas de esquiva e da utilização do procedimento de bloqueio de esquiva através da análise de uma relação terapêutica (Dissertação de mestrado). Pontifícia Universidade Católica de São Paulo, São Paulo.

Greenberg, L. S., \& Pinsof, W. M. (1986). The psychotherapeutic process: A research book. New York: The Guilford Press.

Hayes, S. C. (1987). A contextual approach to therapeutic change. In: N. S. Jacobson (Org.), Psychoterapists in clinical practice: Cognitive and behavioral perspectives (pp. 327-387). New York: Guilford Press.

Hill, C. E. (1978). The development of a system for classifying counselor responses. Journal of Counseling Psychology, 25, 461-468.

Hill, C. E. (1986). An overview of the Hill counselor and client verbal response mode category systems. Em L. S. Greenberg \& W. M. Pinsof (Eds.), The psychotherapeutic process: A research handbook. New York: The Guilford Press.

Hill, C. E., Corbett, M. M., Kanitz, B., Rios, P., Lightsey, R., \& Gomez, M. (1992). Client behavior in counseling and therapy sessions: Development of a pantheoretical measure. Journal of Counseling Psychology, 39, 539-549.

Holland, J. G., \& Skinner, B. F. (1975) A análise do comportamento. São Paulo: EPU. (Trabalho original publicado em 1969).

Kameyama, M. (2011). Efeitos de relatos de sentimentos em supervisão sobre o desempenho em sessão do terapeuta analítico-comportamental (Qualificação de mestrado). Universidade de São Paulo, São Paulo.

Kazdin, A. E. (2002). Methodology: General lessons to guide research. Em A. E. Kazdin (Org.), Methodological issues \& strategies in clinical research (Vol. 3, pp. 877-888). Washington: American Psychological Association.

Kohlenberg \& Tsai, (1991). Functional analytic psychotherapy: Creating intense and curative therapeutic relationships. New York: Plenum.

Lima, M. N., \& Lopes, R. T. (2006). A avaliação da sessão terapêutica em diferentes abordagens: Uma análise da percepção e sentimentos do terapeuta e do cliente (Trabalho de conclusão de curso). Universidade São Judas Tadeu, São Paulo.

Luna, S. V. (1997). O terapeuta é um cientista? Em R. A. Banaco (Org.), Sobre comportamento e cognição: Vol. 1. Aspectos teóricos, metodológicos e de formação em análise do comportamento e terapia cognitivista (pp. 299-307). Santo André: ESETec.

Maciel, J. M. (2004). Terapia analítico-comportamental e ansiedade: Análise da interação verbal terapeuta-cliente (Dissertação de mestrado). Universidade Federal do Pará, Belém.

Mahl, G. F. (1987). Exploration in nonverbal and vocal behavior. New Jersey: Laurence Erlbaum Associates.

Margotto, A. (1998). Identificando mudanças na interação verbal em situação clínica (Dissertação de mestrado). Universidade de São Paulo, São Paulo.

Marinotti, M. (2000). Categorização: Agrupando comportamentos ou eventos em classes. Texto elaborado para uso interno na disciplina "Observação como Fonte de Dados na Análise do Comportamento" do Programa de Estudos Pós-Graduados em Análise do Comportamento da Pontifícia Universidade Católica de São Paulo, São Paulo.

Marques, E. (2009). Classificação dos comportamentos verbais vocais do terapeuta de casal a partir de um sistema multidimensional de categorização (Monografia de especialização). Núcleo Paradigma de Análise do Comportamento, São Paulo.

Martins, P. (1999). Atuação de terapeutas estagiários com relação a falas sobre eventos privados em sessões de psicoterapia comportamental (Dissertação de mestrado). Belém: Universidade Federal do Pará.

Meyer, S. B., \& Donadone, J. (2002). O emprego da orientação por terapeutas comportamentais. Revista Brasileira de Terapia Comportamental e Cognitiva, 4(2), 79-90.

Meyer, S. B. \& Vermes, J. S. (2001). Relação terapêutica. Em: B. Range (Org.), Psicoterapias cognitivo-comportamentais: Um diálogo com a psiquiatria. São Paulo: Artmed.

Moreira, S. B. S. (2001). Descrição de algumas variáveis em um procedimento de supervisão de te- 
rapia analítica do comportamento (Dissertação de mestrado).Pontifícia Universidade Católica de São Paulo, São Paulo.

Nardi, R. (2004). Proposta de método de interpretação da interação terapeuta-cliente: Análise comportamental da esquiva através do comportamento verbal de terapeuta e cliente em um caso de dor crônica (Dissertação de mestrado). Universidade de São Paulo, São Paulo.

Novaki, P. (2003). Influência da experiência e de modelo na descrição de intervenções terapêuticas (Dissertação de mestrado). Universidade de São Paulo, São Paulo.

Oliveira, S. C. (2002). A interpretação na terapia comportamental: Um estudo exploratório com uma terapeuta em treinamento (Dissertação de mestrado). Universidade de Brasília, Brasília.

Oshiro, C. K. B. (2011). Efeitos de intervenções baseadas em análises de contingências extrassessão e na psicoterapia analítica funcional (Qualificação de Doutorado). Universidade de São Paulo, São Paulo.

Pérez-Álvarez, M. P. (1996). La psicoterapia desde el punto de vista conductista. Madrid: Biblioteca Nueva.

Pinto, M. G. A. (2007). Um estudo sobre relações entre o dizer e o fazer: Algumas variáveis que operam no controle do planejamento de sessões terapêuticas. (Dissertação de mestrado). Pontifícia Universidade Católica de São Paulo, São Paulo.

Rice, L. N., \& Kerr, G. P. (1986). Measures of client and therapist vocal quality. Em L. S. Greenbert \& W. M. Pinsof (Eds.), The psychotherapeutic process: A research handbook. New York: Guilford Press.

Rocha, G. V. M (2008). Psicoterapia analítico-comportamental com adolescentes infratores de alto-risco: Modificação de padrões anti-sociais e diminuição da reincidência criminal (Tese de doutorado). Universidade de São Paulo, São Paulo.

Rossi, P. R. (2011). Categorização de sessões iniciais de psicoterapias bem e mal sucedidas. (Qualificação de mestrado). Universidade de São Paulo, São Paulo.

Rubba, G. A., \& Leite, J. P. (2006). As intervenções do terapeuta em diferentes abordagens: Categorização e análise das relações funcionais
(Trabalho de conclusão de curso). Universidade São Judas Tadeu, São Paulo.

Russel, R. L., \& Trull, T. (1986). Sequential analyses of language variables in psychotherapy process research. Journal of Consulting and Clinical Psychology, 54(1), 16-21.

Sadi, H. M. (2010). Análise dos comportamentos de terapeuta e cliente em um caso de transtorno de personalidade borderline. (Qualificação de doutorado). Universidade de São Paulo, São Paulo. Schindler, L., Hohenberger-Sieber, E., \& Hahlweg, K. (1989). Observing client-therapist interaction in behavior therapy: Development and first application of an observational system. British Journal of Clinical Psychology, 28, 213-226.

Silva, A. S. (2001). Investigação dos efeitos do reforçamento na sessão terapêutica sobre os relatos de eventos privados, relatos de relações entre eventos privados e variáveis externas e relatos de relações entre eventos ambientais e respostas abertas (Dissertação de mestrado). Pontifícia Universidade Católica de São Paulo, São Paulo.

Silveira, F. F. (2007). Intervenção com cuidadoras em grupo: Descrição da atuação do terapeuta sob uma perspectiva comportamental (Dissertação de mestrado). Universidade de São Paulo, São Paulo.

Skinner, B. F. (1972). Tecnologia do ensino. São Paulo: Herder. (Trabalho original publicado em 1968).

Stiles, W. B. (1980). Measurement of the impact of psychotherapy sessions. Journal of Consulting and Clinical Psychology, 48, 176-185.

Stiles, W. B. (1992). Describing talk: A taxonomy of verbal response modes. Newbury Pak: Sage.

Suen, H. K., \& Ary, D. (1989). Analyzing quantitative behavioral observation data. New Jersey: Lawrence Erlbaum Associates.

Tourinho, E. Z, Garcia, M. G., \& Souza, L. M. (2003). Avaliação ampliada de categorias para análise de verbalizações de terapeutas. Projeto de pesquisa. Universidade Federal do Pará, Belém.

Vermes, J. S. (2000). Uma avaliação dos comportamentos do terapeuta durante a sessão: Relatos verbais do terapeuta e do cliente (Relatório final de iniciação científica). Pontifícia Universidade Católica de São Paulo, São Paulo. 
Wampold, B. E. (1986). State of the art in sequential analysis: Comment on Lichtenberg and Heck. Journal of Counseling Psychology, 33(2), 182-185.

Xavier, R. N. (2010). Microanálise da modelagem de repertórios em um estudo de caso de terapia analítico-comportamental infantil (Qualificação deMestrado). Universidade de São Paulo, São Paulo.

Yano, Y. (2003). Tratamento padronizado e individualizado no transtorno do pânico (Tese de doutorado).Universidade de São Paulo, São Paulo.

Zamignani, D. R. (2001). Uma tentativa de caracterização da prática clínica do analista do comportamento no atendimento de clientes com e sem o diagnóstico de transtorno obsessivo-compulsivo (Dissertação de mestrado).Pontifícia Universidade Católica de São Paulo, São Paulo.

Zamignani, D. R. (2007). O desenvolvimento de um sistema multidimensional para a categorização de comportamentos na interação terapêutica (Tese de doutorado). Universidade de São Paulo, São Paulo.

Zamignani, D. R., \& Andery, M. A. P. A. (2005). Interação entre terapeutas comportamentais e clientes diagnosticados com transtorno obsessivo-compulsivo. Psicologia: Teoria e Pesquisa, 21(1), 109-119.

\section{Informações do artigo}

\section{História do artigo}

Data de submissão em: 17/12/2010

Primeira decisão editorial em: 03/03/2011

Aceito para publicação em: 22/06/2011 